Graziele G. Bovi, Guido Rux, Oluwafemi J. Caleb, Werner B. Herppich, Manfred Linke, Cornelia Rauh, Pramod V. Mahajan

\title{
Measurement and modelling of transpiration losses in packaged and unpackaged strawberries
}

Journal article | Accepted manuscript (Postprint)

This version is available at https://doi.org/10.14279/depositonce-9719

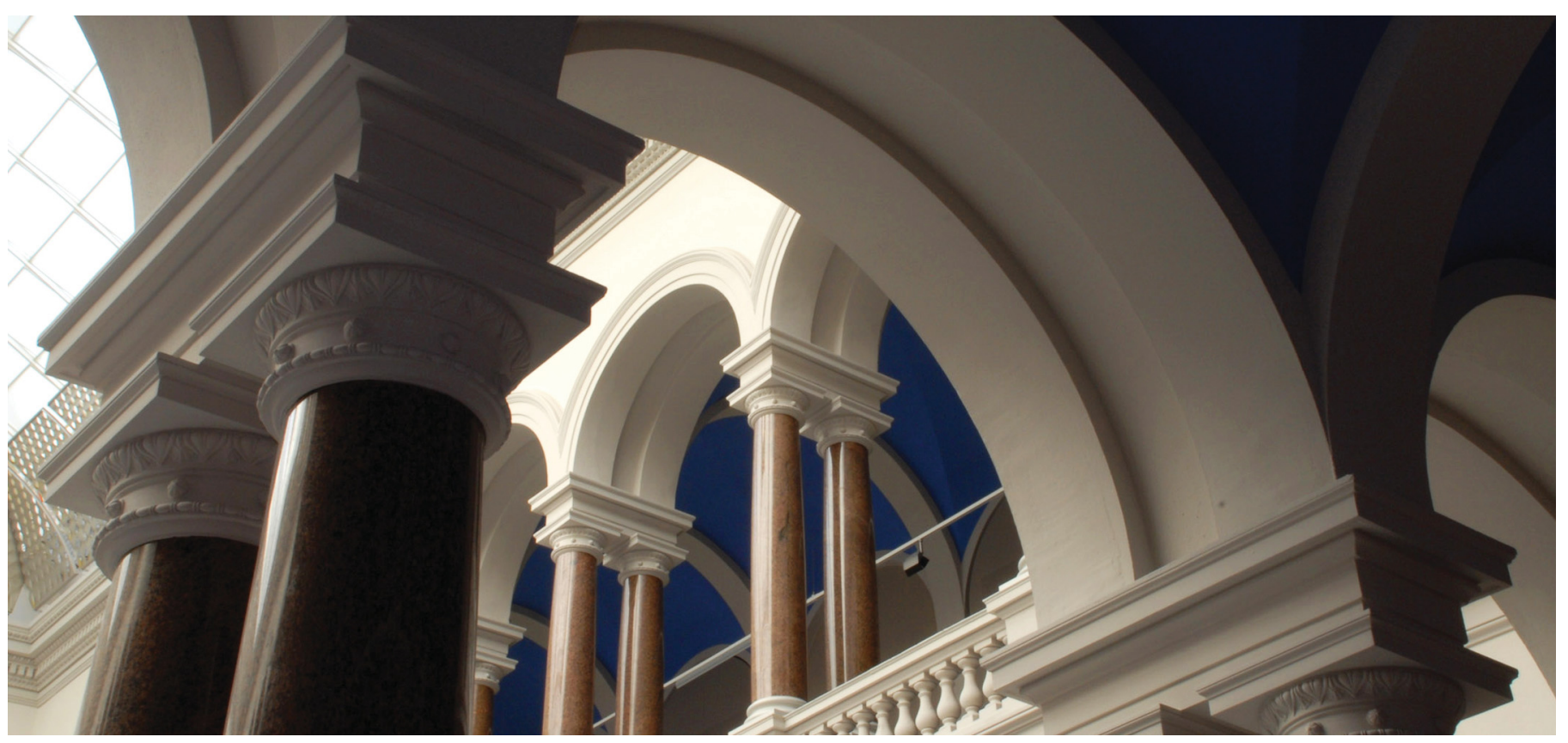

Bovi, G. G., Rux, G., Caleb, O. J., Herppich, W. B., Linke, M., Rauh, C., \& Mahajan, P. V. (2018).

Measurement and modelling of transpiration losses in packaged and unpackaged strawberries. Biosystems Engineering, 174, 1-9. https://doi.org/10.1016/j.biosystemseng.2018.06.012 
1 Measurement and modelling of transpiration losses in packaged and 2 unpackaged strawberries

3

4 In: Biosystems Engineering 174, 1-9.

5

6

7 Cite as: Bovi, G.G., Rux, G., Caleb, O.J., Herppich, W.B., Linke, M., Rauh, C., \& Mahajan,

8 P.V., (2018). Measurement and modelling of transpiration losses in packaged and unpackaged

9 strawberries. Biosystems Engineering, 174, 1-9.

10 doi: https://doi.org/10.1016/j.biosystemseng.2018.06.012

11

12

13

14

15

16

17

18

19

20

21

22

23

24

25

26 


\title{
Measurement and modelling of transpiration losses in packaged and unpackaged strawberries
}

\author{
Graziele G. Bovi ${ }^{\text {a, b, }}$, Guido Rux ${ }^{\text {a }}$, Oluwafemi J. Caleb ${ }^{\text {a,c }}$, Werner B. Herppich ${ }^{\mathrm{a}}$, Manfred Linke ${ }^{\mathrm{a}}$, \\ Cornelia Rauh ${ }^{\mathrm{b}}$, Pramod V. Mahajan ${ }^{\mathrm{a}}$
}

${ }^{\mathrm{a}}$ Department of Horticultural Engineering, Leibniz Institute for Agricultural Engineering and Bioeconomy (ATB), Potsdam, Germany

${ }^{\mathrm{b}}$ Department of Food Biotechnology and Food Process Engineering, Technical University of Berlin, Germany

${ }^{\mathrm{c}}$ Division of Post-harvest and Agro-processing Technologies, Agricultural Research Council (ARC) InfruitecNietvoorbij, Stellenbosch 7599, South Africa

*Corresponding author: Phone: +49(0)3315699628;

E-mail: gbovi@atb-potsdam.de (Graziele G. Bovi); pmahajan@atb-potsdam.de (Pramod V. Mahajan)

\section{Abstract}

Transpiration and respiration are physiological processes well-known as major sources of fresh produce mass loss. Besides causing impairment of external quality, it is associated with economic loss since it inevitably decreases saleable weight. To prevent postharvest mass losses, by improved modified atmosphere and humidity packaging, comprehensive knowledge on the mechanistic basis of both processes and their interactions is essential. The objective of this study was to evaluate the contribution of these processes on mass loss of packaged and unpackaged strawberries. Experiments on a single strawberry were performed at 4, 12 and $20^{\circ} \mathrm{C}$; and 76, 86, 96 and $100 \% \mathrm{RH}$. Mass loss was also investigated as a function of number of strawberries and package volume at $12^{\circ} \mathrm{C}$. A combined model based on Arrhenius equation and Fick's first law of diffusion for an unpackaged single strawberry and a model based on degree of filling was developed and validated with packaged strawberries. These models have potential application towards the selection of optimal moisture control strategies for strawberries.

Keywords: Modified atmosphere and humidity packaging, Water loss, Strawberry, Transpiration, Degree of filling (DOF) 


\begin{tabular}{|c|c|c|}
\hline 64 & \multicolumn{2}{|c|}{ Nomenclature } \\
\hline 65 & DOF & Degree of filling \\
\hline 66 & MAP & Modified atmosphere packaging \\
\hline 67 & MAHP & Modified atmosphere and humidity packaging \\
\hline 68 & RH & Relative humidity (\%) \\
\hline 69 & TR & Transpiration rate \\
\hline 70 & $\mathrm{RR}$ & Respiration rate \\
\hline 71 & VPD & Water vapour pressure deficit \\
\hline 72 & $\mathrm{TR}_{\mathrm{m}}$ & Transpiration rate on mass basis $\left(\mathrm{g} \mathrm{kg}^{-1} \mathrm{~h}^{-1}\right)$ \\
\hline 73 & $\mathrm{~m}_{\mathrm{i}}$ & Initial mass of the product $(\mathrm{g})$ \\
\hline 74 & $\mathrm{~m}_{\mathrm{t}}$ & Product mass $(\mathrm{g})$ at a determined time $(\mathrm{t})$ in hours $(\mathrm{h})$ \\
\hline 75 & $\mathrm{P}_{\mathrm{s}}$ & Saturation vapour pressure $(\mathrm{kPa})$ \\
\hline 76 & $\mathrm{P}_{\mathrm{a}}$ & Actual vapour pressure $(\mathrm{kPa})$ \\
\hline 77 & $\mathrm{~T}$ & Surrounding temperature $\left({ }^{\circ} \mathrm{C}\right)$ \\
\hline 78 & BOPP & Bi-axially oriented polypropylene \\
\hline 79 & $\mathrm{~K}_{\mathrm{i}}$ & Mass transfer coefficient \\
\hline 80 & $\mathrm{a}_{\mathrm{wi}}$ & Water activity of the commodity \\
\hline 81 & $\mathrm{a}_{\mathrm{w}}$ & Water activity of the storage air \\
\hline 82 & a & Model constant coefficient \\
\hline 83 & $\mathrm{M}_{\text {sub }}$ & Mass loss due to substrate \\
\hline 84 & TMLR & Total mass loss rate \\
\hline 85 & $\mathrm{~V}_{\text {product }}$ & Product's volume (mL) \\
\hline 86 & $\mathrm{~V}_{\text {package }}$ & Package's volume (mL) \\
\hline
\end{tabular}

\section{1. Introduction}

89 Modified atmosphere packaging (MAP) systems have been extensively used to reduce

90 physiological activity of fresh produce by modifying in-package gas composition as well as to 91 reduce mass loss by maintaining high in-package air humidity (Caleb, Mahajan, Al-Said, \& 92 Opara, 2013a). Most of the packaging materials used for MAP have low water vapour 93 permeability, and, therefore, the water vapour released by the product due to transpiration 94 remains trapped inside the package, often leading to undesirable condensation (Bovi, Caleb, 95 Linke, Rauh, \& Mahajan, 2016). Thus, in order to lessen in-package water vapour 96 condensation it is essential to shift the system design from MAP to modified atmosphere and 97 humidity packaging (MAHP). The main challenge of MAHP is to reduce condensation while 
still maintaining produce water loss as low as possible (Rodov, Ben-Yehoshua, Aharoni, \& Cohen, 2010). The design based on MAHP not only takes into account the gas composition but also the in-package air humidity and moisture control strategies to maintain desirable relative humidity (RH) and thus reduce condensation (Bovi \& Mahajan, 2017).

In order to design appropriate MAHP it is essential to understand how much water is released by the product. Water loss in fresh produce is commonly measured by quantifying the amount or the mass of water lost per unit of time, the transpiration rate (TR). Many models based on Fick's first law of diffusion have been proposed to calculate the TR of a wide range of horticulture products such as strawberry (Sousa-Gallagher et al., 2013), pomegranate arils (Caleb, Mahajan, Al-Said, \& Opara, 2013b), whole mushroom (Mahajan, Oliveira, \& Macedo, 2008), tomatoes (Xanthopoulos, Athanasiou, Lentzou, Boudouvis, \& Lambrinos, 2014), and pears (Xanthopoulos, Templalexis, Aleiferis, \& Lentzou, 2017). These models are efficient and valid for single unpackaged products, but their application in a dynamic system to estimate the TR of packaged products have not yet been tested.

Furthermore, the quantity of mass loss over a given period of time has long been accepted as being the TR of fresh produce. This was based on the assumption that mass loss due to the oxidative breakdown of organic reserves (substrate loss) and the effects that respiration exerts on TR, by generating metabolic heat and by supplying additional water that can be lost in transpiration, are negligible (Shirazi \& Cameron, 1993; Xanthopoulos et al., 2017). Recent studies, however, have pointed out the important role respiration plays on TR of fresh produce, under water vapour saturated environments which is normally seen in packaged fresh produce (Bovi, Caleb, Herppich, \& Mahajan, 2018). For instance, Mahajan et al. (2016) developed a model to calculate TR based on respiration rate (RR). The authors calculated this effect on TR by multiplying RR with a conversion factor of 8.6 obtained from the respiratory heat and adding it to model of TR calculations based on Fick's first law of diffusion. Furthermore, the authors indicated that the heat of respiration increased the surface temperature of fresh mushroom above that of the surrounding air, thereby creating a water vapour pressure deficit (VPD) that may further drive transpirational water losses. In addition, Xanthopoulos et al. (2017) developed a model that analyses the contribution of transpiration and respiration on water loss using pears as a model product. Water loss indirectly resulting from respiration accounts for $39 \%$ of the total water loss as a result of water vapour pressure deficit at an air temperature of $20{ }^{\circ} \mathrm{C}$ and $95 \% \mathrm{RH}$. 
130 The critical challenge in modelling TR and, consequently, water loss in fresh produce is that 131 the parameters and/or coefficients of the model are product specific. Similarly, the appropriate moisture control strategy also needs to be product specific and has to be optimized considering the transpirational properties of each fruit or vegetable (Bovi, Caleb, Klaus, et al., 2018). This challenge implies that the respective physiological features of each type of fresh produce needs to be studied in detail and individually under each different storage condition and packaging system. In this context, the aim of this work was to develop a model to predict water loss from packaged fresh produce, with the potential application towards the selection of optimal moisture control strategies. With this aim, a comprehensive case study was carried out on the mass loss of packaged and unpackaged strawberries.

\section{Materials and methods}

\section{2.1. Sample preparation}

142 Freshly harvested strawberries were obtained from a commercial supplier (Obst und Gemüse 143 Großhandle, Beusselstraße, Berlin) and immediately transported to the Department of 144 Horticultural Engineering, Leibniz Institute for Agricultural Engineering and Bioeconomy, 145 Potsdam, Germany. The strawberries were carefully sorted for uniformity in size and colour, 146 and damaged, overripe and poor quality samples were discarded.

$147 \mathrm{CO}_{2}$-based respiration rates $(\mathrm{RR})$ of strawberries were determined by continuously monitoring 148 rates of $\mathrm{CO}_{2}$ production by a novel closed-system respirometer previously described by Rux, 149 Caleb, Geyer, and Mahajan (2017). The respirometer consisted of acrylic glass cuvettes (8.2 $150 \mathrm{~L}$ ), each fitted with non-dispersive infrared $\mathrm{CO}_{2}$ sensor (GMP222, Vaisala GmbH, Bonn, 151 Germany). The RR was calculated as the amount of $\mathrm{CO}_{2}$ per unit mass of the fruit per unit 152 time $\left(\mathrm{mg} \mathrm{CO}_{2} \mathrm{~kg}^{-1} \mathrm{~h}^{-1}\right)$. Measurements were carried out for $6 \mathrm{~h}$ at 4,12 and $20{ }^{\circ} \mathrm{C}$.

\section{2.2. Transpiration rate of single unpacked strawberries}

154 The experimental setup consisted of four containers (190 1) located in walk-in cold rooms with adjustable temperature. Three temperatures $\left(4,12\right.$ and $\left.20^{\circ} \mathrm{C}\right)$ at four different $\mathrm{RH}$ were tested. The RH (\%) inside each of the container was adjusted independently by using various saturated salt solutions made from analytical grade reagents of sodium chloride, potassium chloride, and potassium nitrate, for $\mathrm{RH}$ of 76,86 , and $96 \%$, respectively, and pure distilled water was used for $100 \%$. Two trays containing saturated salt solutions were placed inside each container and a wire mesh was placed above the trays to hold the petri-dishes containing the individual strawberries. TR was calculated by a gravimetric approach according to: 


$$
T R_{m}=\frac{m_{i}-m_{t}}{t \cdot\left(\frac{m_{i}}{1000}\right)}
$$

163 where $T R_{m}$ is the transpiration rate on mass basis $\left(\mathrm{g} \mathrm{kg}^{-1} \mathrm{~h}^{-1}\right), m_{i}$ is the initial mass of the 164 product $(\mathrm{g}) ; m_{t}$ is product mass $(\mathrm{g})$ at a determined time $(\mathrm{t})$ in hours $(\mathrm{h})$. A total of five repetitions were carried out for each treatment and the mass loss was measured daily using an electronic balance CPA10035 (Sartorius, Göttingen, Germany). The VPD for every temperature and $\mathrm{RH}$ was calculated according to the equation presented by Matyssek and Herppich (2017):

$$
V P D=P_{s}-P_{a}
$$

where $\mathrm{P}_{\mathrm{s}}$ is the saturation vapour pressure (Eq. 3) and $\mathrm{P}_{\mathrm{a}}$ is the actual vapour pressure (Eq. 4).

$$
\begin{gathered}
P_{S}=\left[\exp \left(52.57633-\frac{6790.4985}{T+273.16}-5.02808 \ln T+273.16\right)\right] \\
P_{a}=P_{s} x R H
\end{gathered}
$$

where $\mathrm{T}$ is surrounding temperature $\left({ }^{\circ} \mathrm{C}\right), \mathrm{RH}$ is relative humidity $(\%)$, and $\mathrm{P}_{\mathrm{s}}$ and $\mathrm{P}_{\mathrm{a}}$ are given 174 in $\mathrm{kPa}$.

175 These equations were further used to calculate the linear variation of TR as a function of VPD. A regression analysis of the linear variation between TR and VPD, for every temperature, was carried out using Microsoft Excel (Office 2010, Microsoft, 116 Germany).

A second set of experiments was performed at $100 \% \mathrm{RH}$, i.e. at water vapour saturation, at 13 ${ }^{\circ} \mathrm{C}$ in a storage chamber (190 1), based on the methodology reported by Mahajan et al. (2016). A single strawberry was hung from the electronic scale using nylon. Distilled water was used

181 in the storage chamber in order to maintain saturated air humidity. Mass loss from the 182 strawberry was continuously monitored using an electronic balance connected to the data logger (ALMEMO 2490, Ahlborn, Holzkirchen, Germany) and its surface temperature was measured using an infrared temperature sensor AMIR 7842 (accuracy $\pm 1 \%$ from value or \pm 1 K) (Ahlborn, Holzkirchen, Germany).

\subsection{Transpiration measurement of packaged strawberries}

187 Two separate experiments were performed in order to evaluate total mass loss of packaged 188 strawberries. In the first experimental set-up, different number of strawberries (1, 3, 6 and 15) 189 were placed inside closed polypropylene containers (0.93 l) weighing (12.26 $\pm 1.73 \mathrm{~g})$; (40.33 $190 \pm 8.80 \mathrm{~g}),(78.57 \pm 12.78 \mathrm{~g})$ and $(215.73 \pm 49.01 \mathrm{~g})$, respectively. A total of six repetitions

191 were carried out and the mass loss of individual strawberries was measured daily using an electronic balance. This experimental data was then used to test the hypothesis that different 
numbers of strawberries packaged in the fixed size of a package $(0.93 \mathrm{l})$ behave differently

194 than a single strawberry.

195 In the second experiment, the mass loss of fixed amount of strawberries $(200 \pm 4 \mathrm{~g})$ placed in packages with different volumes was evaluated. For this investigation, three different polypropylene packaging trays were used: a small (0.8 1), a medium (1.4 1), and a large (2.3 1); and the proportion of strawberry per package size (strawberry volume: package volume) was $1: 4,1: 7$, and 1:12, respectively. All packages were filled with strawberries and covered with bi-axially oriented polypropylene (BOPP) PropafilmTM RGP25 (25 mm thickness; permeability rate to $\mathrm{O}_{2}, 8.5 \times 10^{-12} \mathrm{~mol} \mathrm{~m}^{-2} \mathrm{~s}^{-1} \mathrm{~Pa}^{-1}$ at $23{ }^{\circ} \mathrm{C}$ and $0 \% \mathrm{RH}$; water vapour, $5.7 \times$ $10^{-6} \mathrm{~mol} \mathrm{~m}^{-2} \mathrm{~s}^{-1} \mathrm{~Pa}^{-1}$ at $23{ }^{\circ} \mathrm{C}$ and $85 \% \mathrm{RH}$, Innovia Films, Cumbria, UK). The covering film on the trays was perforated with 6,5 , and 4 micro-perforations of diameter $0.82 \mathrm{~mm}$, for the small, medium, and large tray, respectively. These perforations were made in order to maintain the package atmosphere close to air and reduce condensation. Packages were stored for $5 \mathrm{~d}$ at $12{ }^{\circ} \mathrm{C}$ and the mass loss of strawberries was measured gravimetrically.

\subsection{Model development and experimental validation}

208 A combined model based on Arrhenius equation and Fick's first law of diffusion for 209 unpackaged single strawberries and a model based on degree of filling (DOF) for packaged strawberries were developed (see section 3.3). Experimental data obtained at all combinations of temperature, $\mathrm{RH}$, and packaging systems studied were used to estimate the values of the coefficients.

213 For the validation of the model based on DOF, strawberries were pre-cooled to the study 214 temperature of $12{ }^{\circ} \mathrm{C}$ for $3 \mathrm{~h}$, and packed (15 strawberries of $200 \pm 10 \mathrm{~g}$ ) in polypropylene 215 trays $(16 \times 12 \times 5 \mathrm{~cm})$, in the proportion of strawberry and package of 1:4. The trays were 216 covered with BOPP and perforated with 6 micro-perforations of diameter $0.82 \mathrm{~mm}$. Packages 217 were stored for $5 \mathrm{~d}$ at $12{ }^{\circ} \mathrm{C}$. Headspace gas composition $\left(\mathrm{O}_{2}\right.$ and $\mathrm{CO}_{2}$ concentrations $)$ inside each package was monitored daily using a CheckMate 3 gas analyser (PBI Dansensor,

219 Ringsted, Denmark). Mass loss was determined by weighing the strawberries at the beginning of the experiment and after storage. Five replicates were carried out.

\subsection{Statistical analysis}

222 The models parameters were determined by fitting the data by non-linear regression analysis and Solver tool in Microsoft Excel (Office 2010, Microsoft, Germany). Furthermore, the data obtained were submitted to analysis of variance (ANOVA) and Tukey's test with significance set at $\mathrm{p}<0.05$ using the Statistica software (version 10.0, StatSoft Inc., Tulsa, USA). 


\section{Results and discussion}

\subsection{Transpiration rate of single unpacked strawberry}

At the lowest RH the TR was highest (Fig.1) because the VPD, i.e. the driving force for transpiration, was generally highest. Raising $\mathrm{RH}$ at $20^{\circ} \mathrm{C}$ from $76 \%$ to $96 \%$, i.e. reducing VPD by approx. $83 \%$ lowered TR by only $43 \%$ from 1.28 to $0.73 \mathrm{~g} \mathrm{~kg}^{-1} \mathrm{~h}^{-1}$. Similarly, with increase in air temperature higher TR was recorded when RH was kept constant. For instance, with the rise in temperature from $4^{\circ} \mathrm{C}$ to $20^{\circ} \mathrm{C}$ at $96 \% \mathrm{RH}$ the TR increased more than 5 times (from 0.13 to $0.73 \mathrm{~g} \mathrm{~kg}^{-1} \mathrm{~h}^{-1}$ ) although VPD increased only approx. threefold from $0.033 \mathrm{kPa}$ to $0.094 \mathrm{kPa}$. These results indicate how both temperature and VPD, or less accurately RH, affect the transpiration. Similar results were found in Sousa-Gallagher, Mahajan, and Mezdad (2013). In their study the TR for strawberries varied from 0.24 to $1.16 \mathrm{~g} \mathrm{~kg}^{-1} \mathrm{~h}^{-1}$ (at 5,10 and $15{ }^{\circ} \mathrm{C}$ and 76,86 and $96 \% \mathrm{RH}$ ), whereas in the present study TR varied from 0.13 to 1.28 (at 4, 12 and $20^{\circ} \mathrm{C}$ and same $\left.\mathrm{RH}\right)$.

This was further highlighted by a comparison of residual transpiration rates in water vapour saturated air (100\% RH), which pronouncedly increased 6.5-fold from $0.02 \mathrm{~g} \mathrm{~kg}^{-1} \mathrm{~h}^{-1}$ at $4{ }^{\circ} \mathrm{C}$ to $0.13 \mathrm{~g} \mathrm{~kg}^{-1} \mathrm{~h}^{-1}$ at $20{ }^{\circ} \mathrm{C}$ (Fig. 1). This clearly indicated that there remained a driving force for transpiration even when the air surrounding the strawberry was water vapour saturated. The driving force for such water loss resulted from a higher fruit body temperature due to heat generated by respiration, which was indeed more than five times higher at $20{ }^{\circ} \mathrm{C}$ that at $4{ }^{\circ} \mathrm{C}$, from 30.26 to $153.18 \mathrm{mg} \mathrm{CO}_{2} \mathrm{~kg}^{-1} \mathrm{~h}^{-1}$ (Fig. 1). The linear variation of TR as a function of VPD is shown in Fig. 2. At VPD $=0 \mathrm{kPa}$ (i.e. $100 \% \mathrm{RH}$ ), there was a residual transpiration rate of $0.1737,0.0675$ and $0.0057 \mathrm{~g} \mathrm{~kg}^{-1} \mathrm{~h}^{-1}$, at 20,12 and $4{ }^{\circ} \mathrm{C}$, respectively. This residual TR resulted from heat of respiration which showed estimated fruit surface temperature of 20.12 ${ }^{\circ} \mathrm{C}, 12.07{ }^{\circ} \mathrm{C}$ and $4.01{ }^{\circ} \mathrm{C}$.

Comparison of the variations of surface temperature of a strawberry and the temperatures of the surrounding air allows visualisation of the effect of respiratory heat generation on strawberry mass loss (Fig. 3). Fruit temperature was indeed higher than that of the surrounding air. This fact implied that the heat of respiration of strawberry increased its surface temperature. In turn, this temperature difference led to an increase in water vapour pressure gradient for the mass transfer between the strawberry and its surrounding conditions and a continuous decline of fruit mass. Therefore, results from this study agree with the hypothesis that respiratory heat can significantly influence water losses from fresh fruit and vegetables under water vapour saturated conditions (Chau \& Gaffney, 1990; Kang \& Lee, 1998). This was also validated by Mahajan et al. (2016) using a mushroom and a spherical 
evaporation dummy apparatus (Linke, Schlüter, \& Geyer, 2008), both stored under water vapour saturated conditions. The mushroom continuously lost mass while that of the evaporation sphere remained constant over time.

\subsection{Transpiration rate as a function of fruit quantity and package volume}

This study showed that increasing the number of strawberries inside a package resulted in lower TR (Fig. 4a). When there was only a single strawberry in the package, the rate of mass loss was $0.068 \mathrm{~g} \mathrm{~kg}^{-1} \mathrm{~h}^{-1}$, whereas with 15 strawberries mean mass losses were less than half that rate, $0.027 \mathrm{~g} \mathrm{~kg}^{-1} \mathrm{~h}^{-1}$. Possible reasons for this reduction could be that: (i) with more strawberries in a package the fresh produce tends to stay closer to each other thereby reducing the effective surface area available for the transpiration and (ii) with more strawberries in the same package volume, saturation is reached more rapidly, and thus the period for decreasing the driving force for transpiration is effectively reduced.

It is well documented that the surface area available for water vapour diffusion plays an important role on fresh produce water loss (Sastry, 1985). Similarly, when strawberries are kept close together their overlaping area reduces the surface available for transpiration and, therefore, water loss is reduced. Furthermore, the time needed for the package to reach water vapour saturation is also important since when the saturation point is reached the TR decreases considerably. Thus, the package headspace plays an indirect, but important, role in water loss because the smaller the headpace, the quicker water vapour saturation is reached. The observations recorded on the effects of varying container volumes on total mass loss (Fig. $4 \mathrm{~b})$, confirmed the hypothesis that package headspace played a major role on mass loss. When the headpace was $0.6 \mathrm{l}$, mass loss was $0.019 \mathrm{~g} \mathrm{~kg}^{-1} \mathrm{~h}^{-1}$; increasing the free headspace to 2.11 (i.e. $\approx 350 \%$ ) the rate of mass loss increased to $0.035 \mathrm{~g} \mathrm{~kg}^{-1} \mathrm{~h}^{-1}(185 \%)$. Therefore, in order to minimise mass loss from fresh produce it is important to minimise package headspace. Overall, these results showed that package headspace played an important role in strawberry mass loss and, therefore, TR measurements of single strawberries measured in large chambers with unrestricted surrounding air flow conditions are not realistic to calculate water loss from packaged fresh produce.

\subsection{Mathematical models}

\subsubsection{Unpackaged strawberries}

Transpiration of fresh produce has been well studied with several reports have been published on mathematical modelling of transpiration rate as a function of extrinsic factors such as 
temperature, RH and air velocity (Bovi et al., 2016; Mahajan et al., 2008; Sastry \& 293 Buffington, 1983). One such model is described by:

$$
\mathrm{TR}=\mathrm{K}_{\mathrm{i}}\left(\mathrm{a}_{\mathrm{wi}}-\mathrm{a}_{\mathrm{w}}\right)\left(1-\mathrm{e}^{-\mathrm{a} T}\right)
$$

where TR is transpiration rate, $K_{i}$ is a mass transfer coefficient, $a_{w i}$ is water activity of the commodity; $\mathrm{a}_{\mathrm{w}}$ is water activity of the storage air, $\mathrm{a}$ is a model constant coefficient and $\mathrm{T}$ is temperature. This model was used to fit the experimental data at 76, 86, and $96 \% \mathrm{RH}$. The model parameters, as well as the comparison between the predicted and experimental data for single unpackaged strawberry are shown in Fig. 5.

As this model was developed for the range 76 to $96 \% \mathrm{RH}$, extrapolating to $100 \% \mathrm{RH}$ (aw = $\mathrm{RH} / 100$ ) would lead to zero TR. This error originated from the assumption that the surface temperature is equal to the temperature of the surrounding air and there is no moisture loss due to respiration heat. Therefore, such model needs to be revised for $100 \% \mathrm{RH}$ and the differences in temperature between the product and the surrounding air should be taken into account. Furthermore, mass measurements also consisted of substrate loss due to respiration. Such loss was calculated using the well accepted equation based on product respiration rate (Kays, 1991; Saltveit, 2004):

$$
M_{\text {sub }}=R R \times\left(\frac{180}{264}\right)
$$

where, $\mathrm{M}_{\text {sub }}$ is the mass loss due to substrate, $\mathrm{RR}$ is the respiration rate in $\mathrm{mg} \mathrm{CO}_{2} \mathrm{~kg}^{-1} \mathrm{~h}^{-1}$ and the ratio 180/264 indicates that when glucose is the substrate, $180 \mathrm{~g}$ of this sugar is lost for each $264 \mathrm{~g}$ of $\mathrm{CO}_{2}$ produced due to respiration reaction. However, this calculation does not take into consideration air humidity and, therefore, the calculated value of $\mathrm{M}_{\text {sub }}$ remained the same despite different water vapour pressure gradients under varying RH. Nevertheless, the calculations were performed and compared to the TR of a single unpackaged strawberries at different RH and temperatures (Fig. 1). The percentage contribution of substrate loss on TR at $\mathrm{RH}$ lower than $96 \%$ was between 3 to $20 \%$. This indicated that the water vapour pressure gradient dominated the transpiration process. However, at saturated humidity (100\%) as normally observed in packaged fresh produce, the contribution of substrate loss on transpiration rate of strawberry was very high $(81-223 \%)$. It is established that the actual transpiration rate or mass loss of fresh produce constitutes not only substrate loss but also moisture loss due to heat of respiration which plays an important role in packaged produce (Bovi, Caleb, Herppich, et al., 2018; Saltveit, 2004). Therefore, this approach to calculating water loss based on substrate loss was not valid in the case of packaged fresh produce where 
RH is very high. Calculation of transpiration rate of packaged fresh produce either based on water vapour pressure gradient due to increase of surface temperature, heat of respiration, substrate loss or carbon loss is still unresolved challenge and needs further attention.

Moreover, other mass flow components such as volatile organic compounds and ethylene, 328 also passing the fruit skin, are usually considered as negligible. Nevertheless, it may be that 329 they also play a role in total mass loss. In this context, the term total mass loss rate (TMLR) 330 will be used in this study, instead of TR, when referring to fresh produce packed in high humidity environments as the mass loss due to substrate, and other mass flow components, might be much more considerable in high humidities.

\subsubsection{Packaged strawberries}

334 For packaged strawberries a TMLR model based on the DOF was proposed. The DOF (\%) was calculated according to:

$$
\text { DOF }=\frac{\text { Vproduct }}{\text { Vpackage }} \times 100
$$

where $\mathrm{V}_{\text {product }}$ is the product's volume $(\mathrm{ml})$ and $\mathrm{V}_{\text {package }}$ is the package's volume $(\mathrm{ml})$. For the calculation of $\mathrm{V}_{\text {product }}$ strawberry density was considered to be $1 \mathrm{~g} \mathrm{ml}^{-1}$.

The analyses of multiple packaged strawberries data showed that there was a negative linear relationship between TMLR and DOF. Therefore, this data was used to develop a simple TMLR model based on the DOF (Fig. 6). It is worth mentioning that this model was only valid when the lidding film used is BOPP as the use of films with different water vapour transmission rate would lead to different values of the TMLR. For instance, Bovi, Caleb, Ilte,

344 Rauh, and Mahajan (2018) reported that strawberries packaged with NatureFlex, Xtend, and 345 Polypropylene film lost $1.46,0.41$, and $0.27 \%$, respectively, of the initial mass during storage 346 conditions at $5{ }^{\circ} \mathrm{C}$ for $14 \mathrm{~d}$. These results showed another challenge of modelling mass loss of 347 packaged products as the permeability of the packaging material used is another important 348 factor to be considered. Moreover, further studies need to be carried out in order to evaluate 349 the effect of the number of micro-perforations on the TMLR of strawberries packaged in 350 BOPP film.

\subsection{Experimental validation using packaged strawberries}

352 In-package gas composition varied between $17-21 \%$ for $\mathrm{O}_{2}$ and $0-4 \%$ for $\mathrm{CO}_{2}$ during $5 \mathrm{~d}$ of 353 storage at $12{ }^{\circ} \mathrm{C}$. After $2 \mathrm{~d}$ of storage, the in-package gas composition of all packages reached 354 equilibrium-modified atmosphere and it effectively maintained $\mathrm{O}_{2}$ and $\mathrm{CO}_{2}$ concentrations of 
17 and 4\%, respectively. Almenar, Catala, Hernandez-Muñoz, and Gavara (2009) reported $\mathrm{O}_{2}$ concentration of up to $14 \%$ for wild strawberries packed in containers covered with polyethylene terephthalate/polypropylene multilayer films with three micro-perforations stored at $10{ }^{\circ} \mathrm{C}$ for $4 \mathrm{~d}$.

Furthermore, results showed that the micro-perforations led to saturated conditions within $1 \mathrm{~h}$ of packaging. This observation can be compared with larger size chamber, 1901 (Fig. 3), with a single strawberry where it reached the water vapor saturation after $10 \mathrm{~h}$. This reinfornced the hypothesis that lower headspace played a major role on TR as it was directly related to the time needed for a system to reach water vapour saturation. The TR of packaged strawberries was $0.03 \pm 0.001 \mathrm{~g} \mathrm{~kg}^{-1} \mathrm{~h}^{-1}$. The initial respiration rate of the packaged strawberries was 33.50 $\pm 1.45 \mathrm{mgCO}_{2} \mathrm{~kg}^{-1} \mathrm{~h}^{-1}$ and after 5 days of storage it was $54.12 \pm 0.40 \mathrm{mgCO}_{2} \mathrm{~kg}^{-1} \mathrm{~h}^{-1}$. Based on the average respiration rate of day 0 and day $5\left(43.81 \mathrm{mgCO}_{2} \mathrm{~kg}^{-1} \mathrm{~h}^{-1}\right)$, the substrate loss for packaged strawberries was $0.03 \mathrm{~g} \mathrm{~kg}^{-1} \mathrm{~h}^{-1}$. This indicates that the contribution of substrate loss on actual measured TR was $100 \%$. Therefore, once again this calculation seems not to be realistic to calculate substrate loss due to respiration.

Moreover, the model based on DOF was used to predict mass loss of packaged strawberries and was then compared with the experimental values (Fig. 7). The predicted mass loss of strawberries packaged with BOPP film was only $446 \mathrm{mg}$ which was much lower than experimental value $(717 \mathrm{mg})$. This experimental value of mass consisted of $20 \mathrm{mg}$ condensation in the tray, $47 \mathrm{mg}$ condensation on the film, and $649 \mathrm{mg}$ transmitted through the micro-perforated packaging film. This analysis showed that it is possible to use water loss predictive model, despite large error, to quantify the amount of moisture in the packaged fresh produce. Such analysis can be used for selection of packaging materials and other active moisture control strategies for controlling humidity and minimising condensation in packaged strawberries. This modelling could eliminate the "pack and pray" approach normally adopted for designing modified atmosphere and modified humidity packaging for respiring fresh products.

\section{Conclusion and future research needs}

A key finding of this study is that headspace plays an important role in mass loss of packaged strawberries and, therefore, the development of a model based on the DOF seems to be an alternative to overcome the difficulties of developing water loss predictive models.

386 Furthermore, the findings of this study raised up some points that should be taken into account for modelling of water loss, such as the deduction of substrate loss and consideration 
388 of the degree of filling. Nevertheless, the question of how to quantify substrate loss in 389 packaged fresh produce still needs to be addressed.

\section{Acknowledgement}

391 This work was supported by Conselho Nacional de Desenvolvimento Científico e 392 Tecnológico (CNPq) through a PhD grant (201623/2015-3). The Georg Forster Postdoctoral 393 Research Fellowship (HERMES) programme from the Alexander von Humboldt Foundation 394 (Ref. ZAF-1160635-GFHERMES-P) is also appreciated.

\section{$395 \quad$ List of Figures}

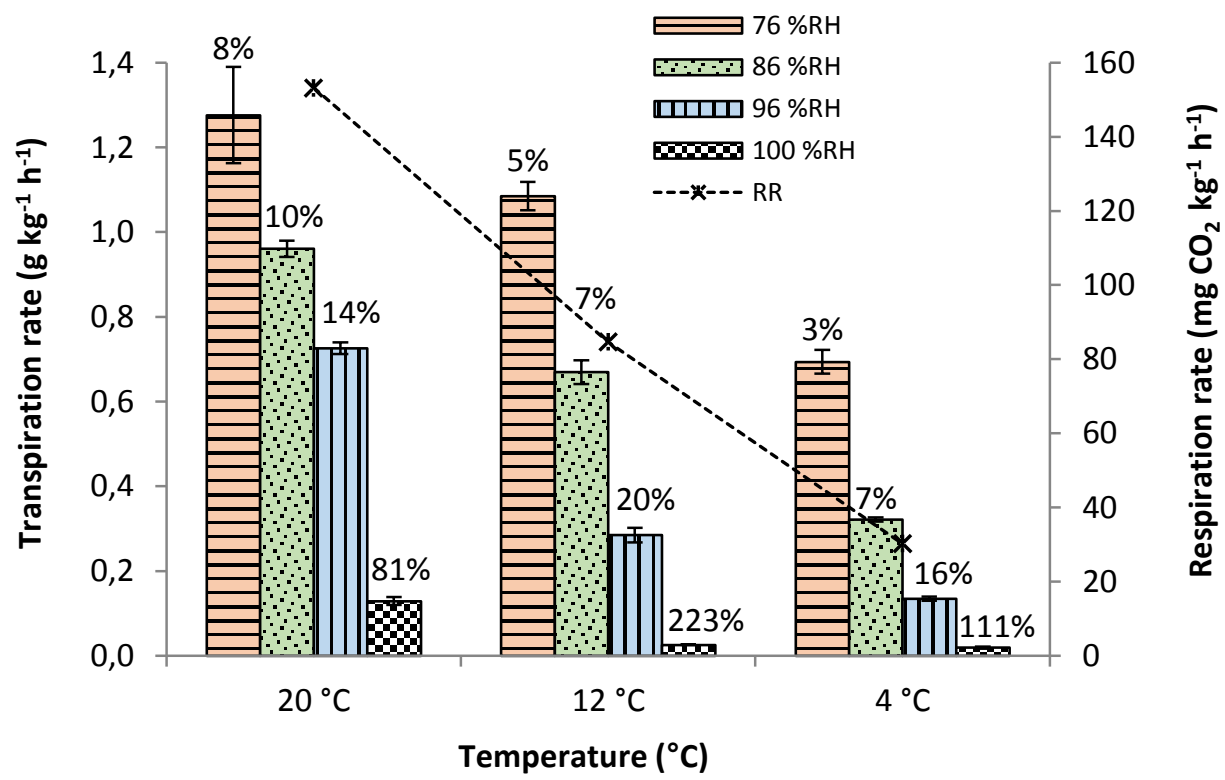

397 Fig. 1 - Transpiration rate of single unpackaged strawberry and respiration rate of 398 strawberries under different storage conditions. The values on top of the bars represent the 399 percentage (\%) of mass loss due to substrate usage or consumption. 


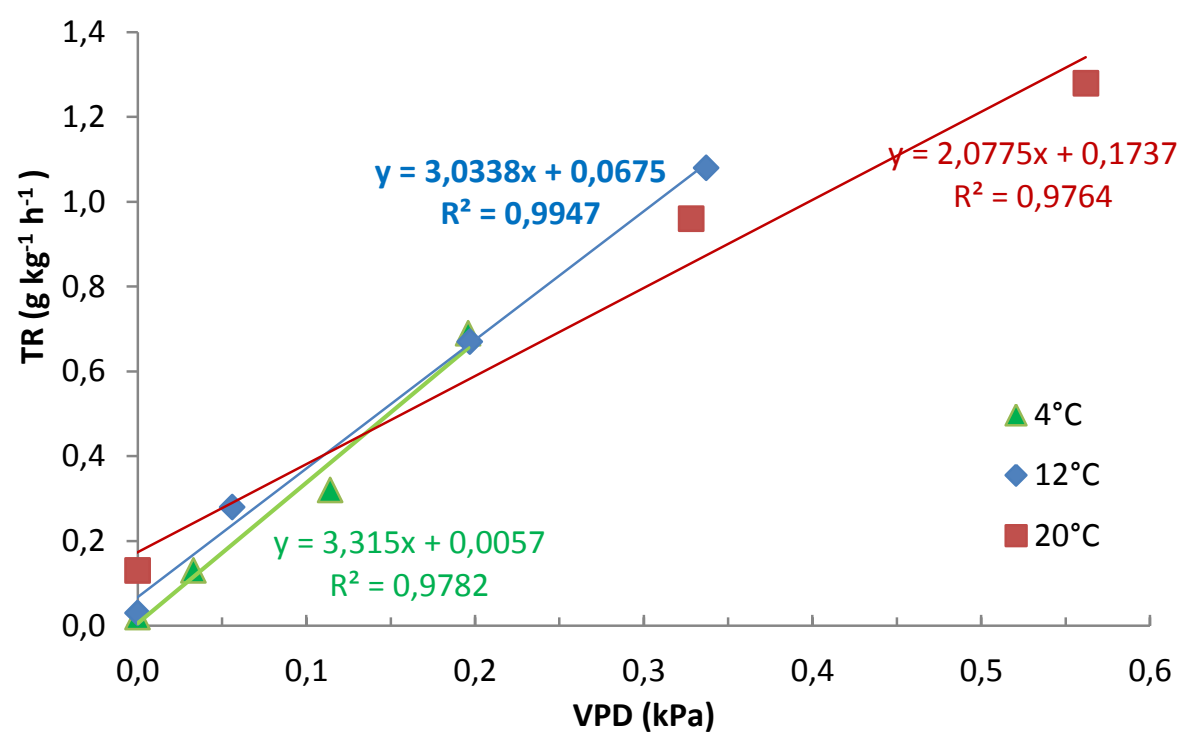

401 Fig. 2 - Experimentally determined transpiration rates (TR) of single unpackaged strawberry 402 versus water vapour pressure deficit (VPD).

Strawberry mass — Relative humidity —Temperature, strawberry -Temperature, air

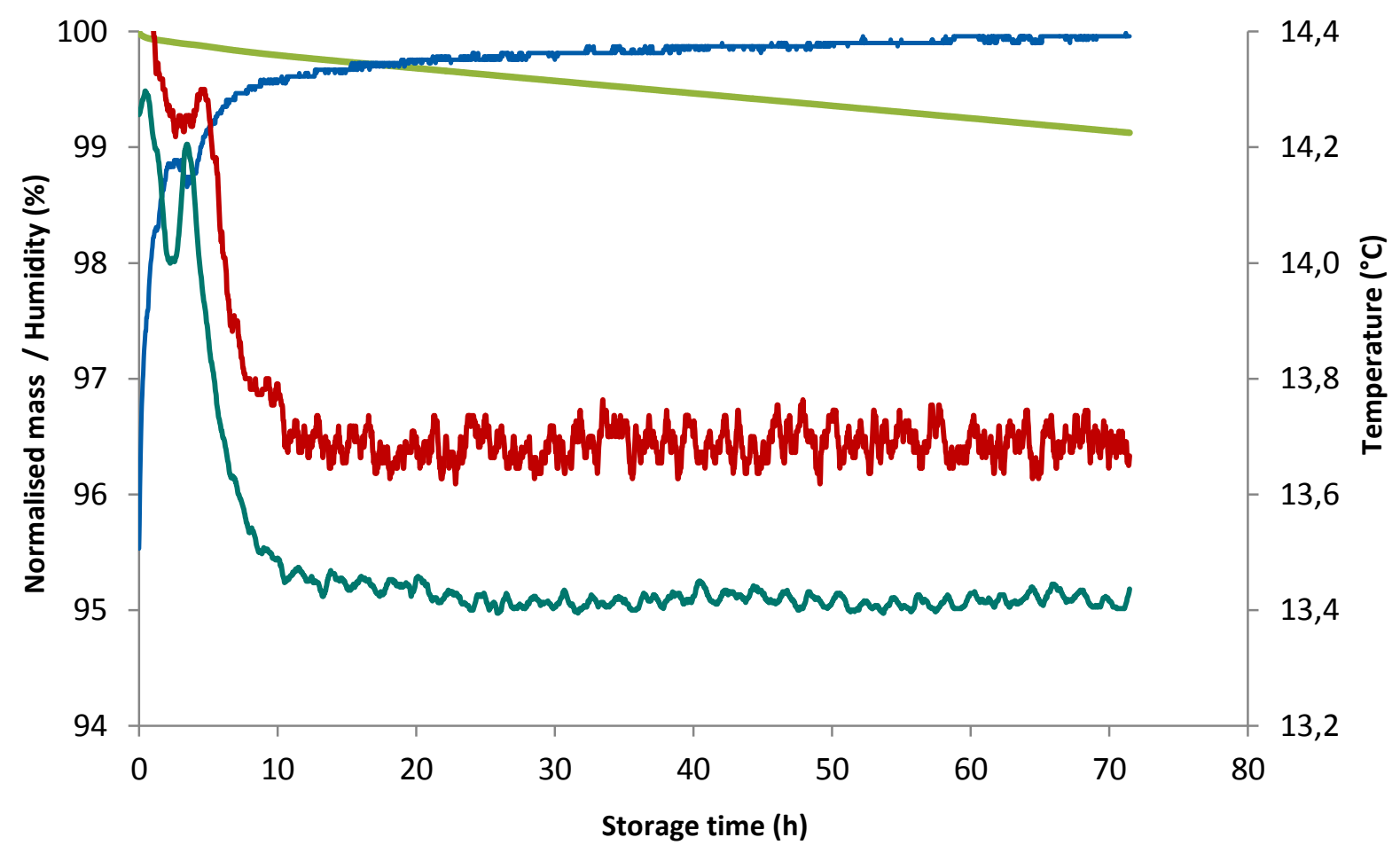

403

404 Fig. 3 - Impact of relative humidity on surface temperature and associated mass loss of a 405 single strawberry. 
(a)

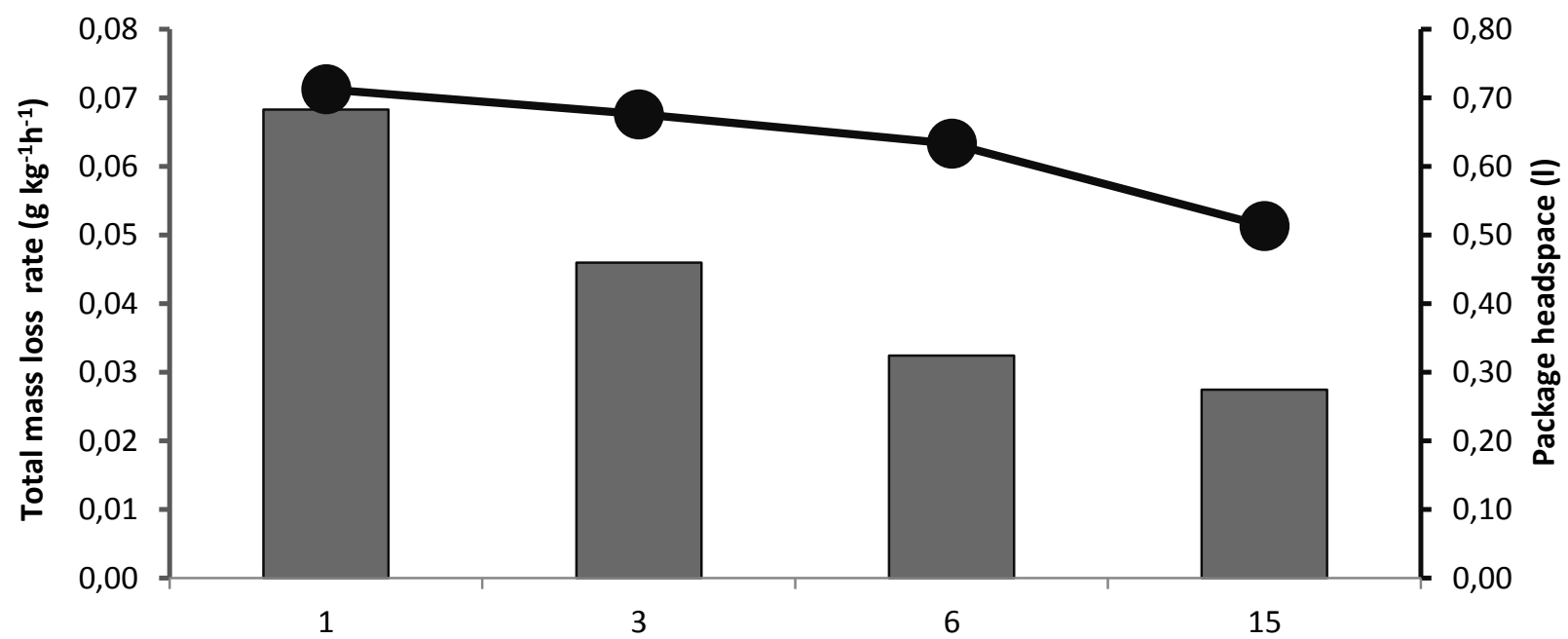

407

(b)

Number of strawberries in a package

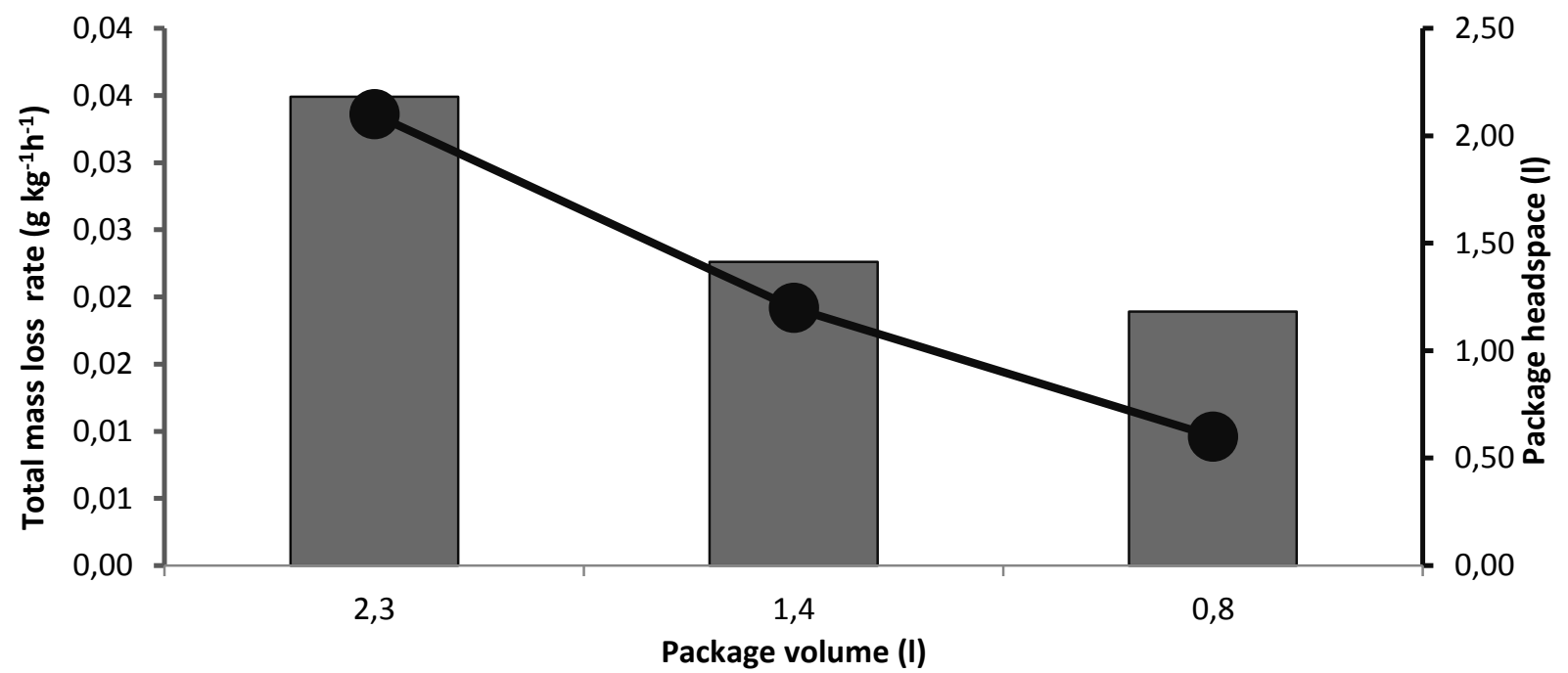

408

409 Fig. 4 - Effect of (a) number of packaged strawberries on total mass loss and (b) container 410 volume on total mass loss of strawberries. The bars represent the total mass loss rate $\left(\mathrm{g} \mathrm{kg}^{-1} \mathrm{~h}^{-1}\right)$ 411 whereas the dots represent the package headspace (1).

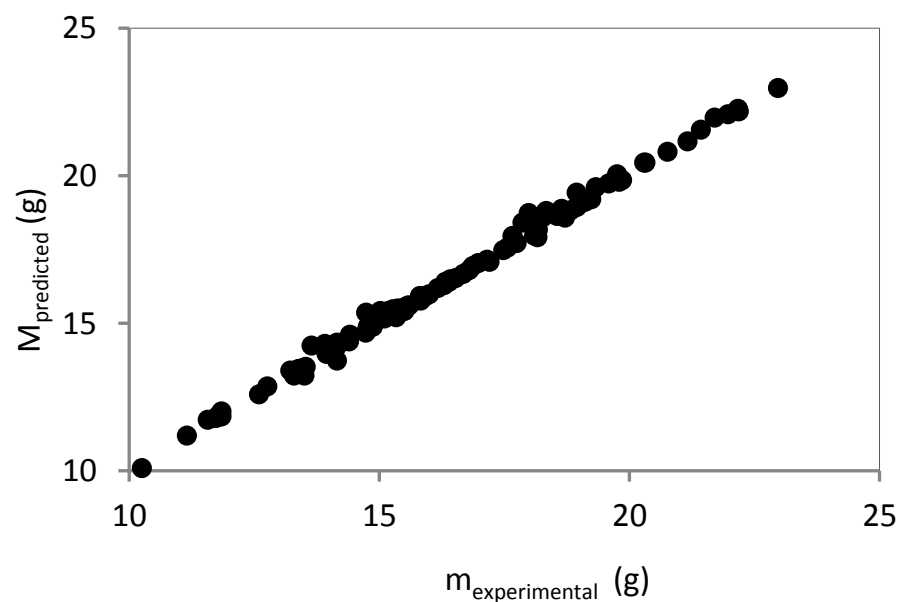

413 Fig. 5 - Description of changes in strawberry mass (g) for predicted versus experimental data, and the model paramenters. 


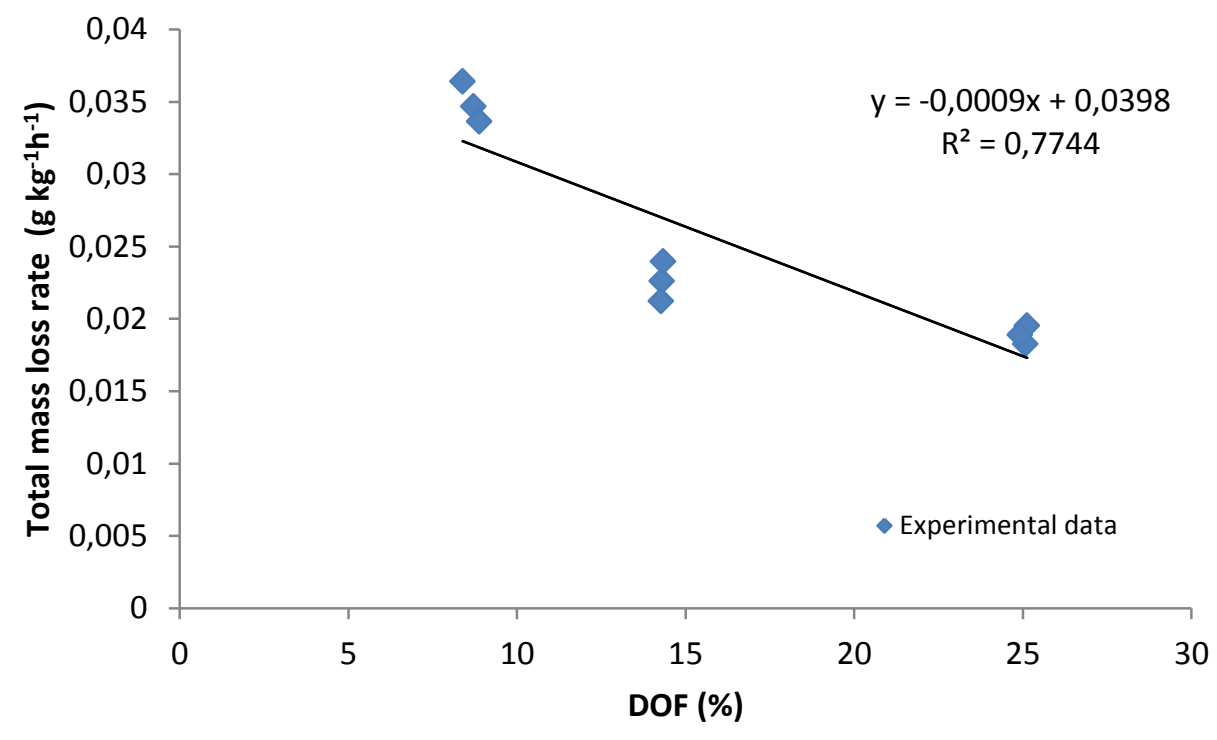

415

416 Fig. 6 - Total mass loss rate of strawberry packaged in containers of different volumes and 417 proposed model based on percentage degree of filling (DOF).

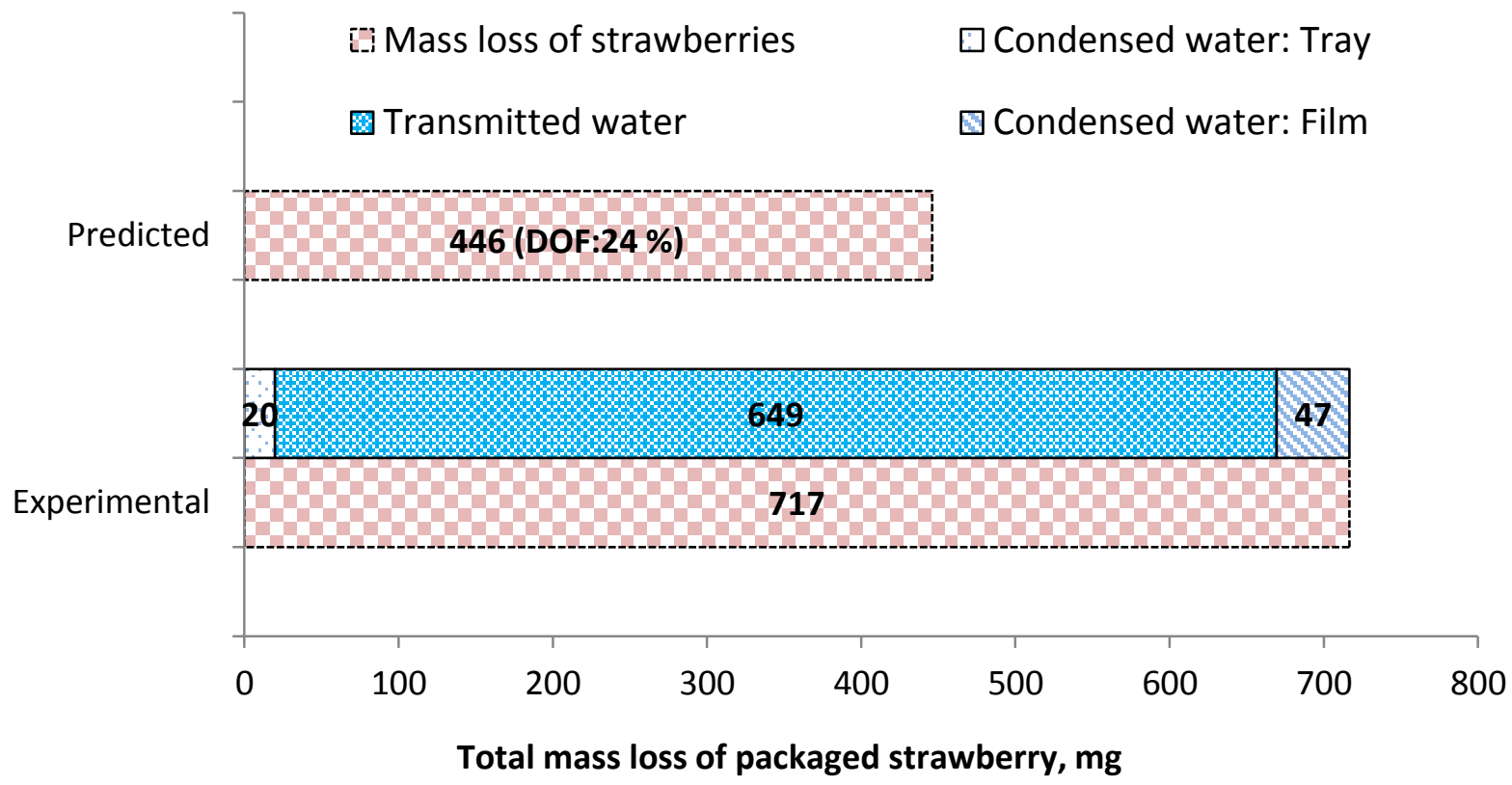

419 Fig. 7 - Experimental distribution of total mass loss in packaged strawberries after $5 \mathrm{~d}$ at 420 storage and the predicted value of total mass loss at $24 \%$ dregree of filling (DOF) at $12{ }^{\circ} \mathrm{C}$. 
Almenar, E., Catala, R., Hernandez-Muñoz, P., \& Gavara, R. (2009). Optimization of an active package for wild strawberries based on the release of 2-nonanone. LWT - Food Science and Technology, 42(2), 587-593. doi: http://dx.doi.org/10.1016/j.lwt.2008.09.009

Bovi, G. G., Caleb, O. J., Herppich, W. B., \& Mahajan, P. V. (2018). Mechanisms and Modeling of Water Loss in Horticultural Products Reference Module in Food Science: Elsevier.

Bovi, G. G., Caleb, O. J., Ilte, K., Rauh, C., \& Mahajan, P. V. (2018). Impact of modified atmosphere and humidity packaging on the quality, off-odour development and volatiles of 'Elsanta' strawberries. Food Packaging and Shelf Life, 16, 204-210. doi: https://doi.org/10.1016/j.fps1.2018.04.002

Bovi, G. G., Caleb, O. J., Klaus, E., Tintchev, F., Rauh, C., \& Mahajan, P. V. (2018). Moisture absorption kinetics of FruitPad for packaging of fresh strawberry. Journal of Food Engineering, 223, 248-254. doi: https://doi.org/10.1016/j.jfoodeng.2017.10.012

Bovi, G. G., Caleb, O. J., Linke, M., Rauh, C., \& Mahajan, P. V. (2016). Transpiration and moisture evolution in packaged fresh horticultural produce and the role of integrated mathematical models: A review. Biosystems Engineering, 150, 24-39. doi: http://dx.doi.org/10.1016/j.biosystemseng.2016.07.013

Bovi, G. G., \& Mahajan, P. V. (2017). Regulation of Humidity in Fresh Produce Packaging Reference Module in Food Science (pp. 1-6): Elsevier.

Caleb, O. J., Mahajan, P. V., Al-Said, F. A., \& Opara, U. L. (2013a). Modified Atmosphere Packaging Technology of Fresh and Fresh-cut Produce and the Microbial Consequences-A Review. Food and Bioprocess Technology, 6(2), 303-329.

Caleb, O. J., Mahajan, P. V., Al-Said, F. A., \& Opara, U. L. (2013b). Transpiration rate and quality of pomegranate arils as affected by storage conditions. CyTA - Journal of Food, 11(3), 199-207.

Chau, K. V., \& Gaffney, J. J. (1990). A Finite-Difference Model for Heat and Mass Transfer in Products with Internal Heat Generation and Transpiration. Journal of Food Science, 55(2), 484-487. doi: 10.1111/j.1365-2621.1990.tb06792.x

Kang, J. S., \& Lee, D. S. (1998). A kinetic model for transpiration of fresh produce in a controlled atmosphere. Journal of Food Engineering, 35(1), 65-73.

Kays, S. J. (1991). Postharvest physiology of perishable plant products: Van Nostrand Reinhold.

Linke, M., Schlüter, O., \& Geyer, M. (2008). A simple atmospheric evaporation device as a useful tool for validation of air flow models and for process control applications. Paper presented at the IV International Symposium on Applications of Modelling as an Innovative Technology in the Agri-Food-Chain: Model-IT, Acta Horticulturae (ISHS), Madrid, Spain.

Mahajan, P. V., Oliveira, F. A. R., \& Macedo, I. (2008). Effect of temperature and humidity on the transpiration rate of the whole mushrooms. Journal of Food Engineering, 84(2), 281-288.

Mahajan, P. V., Rux, G., Caleb, O. J., Linke, M., Herppich, W., \& Geyer, M. (2016). Mathematical model for transpiration rate at $100 \%$ humidity for designing modified humidity packaging. Paper presented at the III International Conference on Fresh-cut Produce. Acta Horticulturae (ISHS), University of California, Davis.

Matyssek, R., \& Herppich, W. B. (2017). Experimentelle Pflanzenökologie: Physik des Wasserdampfes - Luftfeuchte und Wasserdampfgradienten Experimentelle Pflanzenökologie. Spektrum, Berlin, Heidelberg: Springer Reference Naturwissenschaften. 
Rodov, V., Ben-Yehoshua, S., Aharoni, N., \& Cohen, S. (2010). Modified Humidity Packaging of Fresh Produce Horticultural Reviews, Volume 37 (pp. 281-329): John Wiley \& Sons, Inc.

Rux, G., Caleb, O. J., Geyer, M., \& Mahajan, P. V. (2017). Impact of water rinsing and perforation-mediated MAP on the quality and off-odour development for rucola. Food Packaging and Shelf Life, 11, 21-30. doi: http://dx.doi.org/10.1016/j.fps1.2016.11.003

Saltveit, M. E. (2004). Respiratory metabolism. The commercial storage of fruits, vegetables, and florist and nursery stocks, 68.

Sastry, S. K. (1985). Moisture losses from perishable commodities: recent research and developments. International Journal of Refrigeration, 8(6), 343-346.

Sastry, S. K., \& Buffington, D. E. (1983). Transpiration rates of stored perishable commodities: a mathematical model and experiments on tomatoes. International Journal of Refrigeration, 6(2), 84-96.

Shirazi, A., \& Cameron, A. C. (1993). Measuring transpiration rates of tomato and other detached fruit. HortScience : a journal of the American Society for Horticultural Science, 28(10), 1035-1038.

Sousa-Gallagher, M. J., Mahajan, P. V., \& Mezdad, T. (2013). Engineering packaging design accounting for transpiration rate: Model development and validation with strawberries. Journal of Food Engineering, 119(2), 370-376.

Xanthopoulos, G. T., Athanasiou, A. A., Lentzou, D. I., Boudouvis, A. G., \& Lambrinos, G. P. (2014). Modelling of transpiration rate of grape tomatoes. Semi-empirical and analytical approach. Biosystems Engineering, 124, 16-23.

Xanthopoulos, G. T., Templalexis, C. G., Aleiferis, N. P., \& Lentzou, D. I. (2017). The contribution of transpiration and respiration in water loss of perishable agricultural products: The case of pears. Biosystems Engineering, 158, 76-85. doi: http://dx.doi.org/10.1016/j.biosystemseng.2017.03.011 
517

518

519

520

521

522

523

524

525

526 